Session 1526

\title{
DEVELOPMENT OF A WIRELESS AND SATELLITE COMMUNICATION LABORATORY AT PENN STATE HARRISBURG
}

\author{
Ali Behagi, Ph.D. \\ Associated Professor of Electrical Engineering \\ Penn State Harrisburg \\ 777 W. Harrisburg Pike \\ Middletown, PA 17057 \\ Phone: 717-948-6379 Fax: 717-948-6401 Email: e0y@psu.edu
}

\section{Summary:}

With the strong support from the National Science Foundation, the Hewlett-Packard Company and the Penn State administration, a state of the art RF and microwave engineering laboratory for undergraduate education has been established. The test and measurement equipment purchased under the NSF-ILI grant has extended the frequency range of measurements from about $100 \mathrm{MHz}$ to over 20,000 MHz. This extended range makes it possible for students to design and evaluate high frequency circuits used in wireless and satellite communication systems.

The HP Eesof Series IV software packages, which were donated to Penn State Harrisburg by the Hewlett-Packard Company in October 1996, are design tools developed especially for the needs of today's RF and microwave engineers. These tools are integrated in a graphical user environment that helps the students to solve design problems from concept to production. To utilize both the hardware and the software more effectively new courses and several new laboratory experiments have been developed.

\subsection{Introduction}

In the US and other industrialized countries, wireless and satellite communication systems such as cellular phone, mobile radio, paging, and satellite radio and TV have become part of peoples' everyday life. In these systems most signal processing is done digitally at low frequencies. However, the small number of unavoidable high frequency analog circuits are the design bottlenecks of an entire system. Three reasons have contributed to this bottleneck. First, the high frequency analog circuit design requires a good understanding of several core courses in the electrical engineering curriculum such as; electromagnetic field theory, antennas and propagation, transmission line theory, communication theory and microwave engineering. In order to cover more digital and computer courses, most electrical engineering programs do not offer or require only some of these courses in their undergraduate education. Second, most IC 
and VLSI circuits which constitute the bulk of low frequency analog and digital systems have no counterpart at wireless and microwave frequencies. Third, the many inexpensive student version of circuit analysis programs such as PSpice and MicroCap III, which help the students to analyze and predict the performance of low frequency and digital circuits, do not exist at wireless and microwave frequencies. As a result the wireless and microwave circuit designer has to rely heavily on intuition and experience rather than computerized design techniques.

Special effort and some innovation is required to offer wireless and microwave engineering courses, with extensive hands-on laboratory experiments, at the undergraduate level. Penn State Harrisburg, thanks to an equipment grant from the National Science Foundation and a high frequency circuit design software donation from HP-EEsof, has developed a laboratory and associated courses for undergraduate education.

In 1987, the Pennsylvania Department of Education extended a grant to Penn State Harrisburg to establish a course in microwave and satellite communication. As a result, a computer-based satellite communication laboratory was established. In addition, the University has purchased laboratory equipment for surface mount and printed circuit board technology for fabrication of wireless and microwave circuits. A brief history of Penn State Harrisburg and the electrical engineering programs now follows.

\subsection{Penn State Harrisburg:}

Penn State Harrisburg was established in 1966, and today remains the only upper division college in Pennsylvania which admits students at the junior level. As an upper division college, Penn State Harrisburg accepts students from the University's two-year campuses, community and junior colleges, and transfer students from other colleges and universities and offers them the opportunity to earn a baccalaureate degree in one of twenty academic majors.

Penn State Harrisburg also is a graduate center and offers master's degree programs, the D.Ed. and the Ph.D. in public administration. The graduate programs are designed primarily for persons employed full-time in area businesses, schools, governmental agencies, and industries. Located in Middletown, PA, eight miles from the state capital at Harrisburg, the college is in an area with a diverse business, cultural, industrial, agricultural, and service base. This diversity offers a multitude of experiential learning opportunities for students and gives faculty access to experts off campus who serve as guest lecturers and teachers. The resources of many local, state, and federal agencies are nearby, as are various museums, archives, and the state library.

\subsection{The Electrical Engineering Programs}

The Electrical Engineering Technology (EET) program at Penn State Harrisburg started in 1967 and produced its first graduates in June 1969. Since then over 2000 students have graduated with the BS degree in EET. Penn State Harrisburg also offers a Master of Engineering in Electrical Engineering with about 40 part time students. A new BS degree in Electrical Engineering is planned to start in 1998. 


\subsection{Course Material}

The material covered in the high frequency circuit design course is based mainly on the textbook by David M. Pozar, Addison-Wesley, 1990. The subjects covered include electromagnetic field theory, transmission line theory, impedance matching, design and fabrication of microwave devices such as: microstrip filters, microwave amplifiers, low noise amplifiers , microwave oscillators , microwave mixers, detectors and phase shifters. Additionally, a microwave engineering course is being offered to graduate students specializing in UHF and Microwave Engineering. To meet the present day industry requirements, these courses have been developed with extensive emphasis on computer-aided design using state of the art microstrip and surface mount technologies. In the newly established laboratory, the students get acquainted with the high frequency components, computer-aided design, fabrication and testing of high frequency circuits using both distributed and lumped elements.

\subsection{Laboratory Experiments}

To give students some design experience, several laboratory experiments have been developed. Following is a partial listing and description of the laboratory experiments.

\subsection{RF and Microwave Amplifier Design}

Today's wireless and satellite communication systems require very tight amplifier specifications especially with regard to noise figure, linearity, and distortion. The vector network analyzer and the spectrum analyzer are used to measure the amplifier S-parameters as well as gain, reflection, stability, power, impedance and noise parameters. Both narrowband and wideband amplifiers at frequencies up to $18 \mathrm{GHz}$ have been designed and fabricated.

\section{2 - RF and Microwave Oscillator Design}

A microwave oscillator basically converts DC power to high frequency power, and so it is one of the most essential components in any wireless or microwave communication system.. A transistor oscillator allows more control of the frequency of oscillation and has better temperature stability and lower output noise than do diode oscillators. The vector network analyzer is used for device characterization of the transistor or the resonator S-parameter measurements. Effective oscillator design requires the consideration of several other issues, such as the selection of an operating point for stable operation and maximum power output, frequency pulling, largesignal effects, and noise characteristics. The Series IV software can optimize the design and offer several types of oscillator analysis, ranging from fully automated to fully manual. Several transistor oscillators such as the Dielectric Resonator Oscillator (DRO), microstrip oscillator, crystal oscillator and coaxial resonator oscillator, up to $12 \mathrm{GHz}$, have been designed and tested. A new software technique for the measurement of the oscillator $\mathrm{Q}$ factors, pulling figure and phase noise has also been developed.

\section{3 - Voltage-Controlled Oscillator Design}

Tunable oscillators are necessary in many types of electronic systems such as communication receivers, frequency-hopping radar, and test and measurement systems. Oscillators are made tunable by using an adjustable element in the resonant load, such as a varactor diode. Several voltage-controlled oscillators using Silicon and GaAs abrupt and 
hyperabrupt varactor diodes have been designed and tested for signal purity, phase noise, $\mathrm{Q}$ factor, and pulling figure.

\subsection{PIN Diode Phase Shifter Design}

Phase shifters control the phase of microwave signals, therefore, they are an important part of any phase-locked loop circuit. Phase shifters are also used to improve the linearity of High-Power Amplifiers (HPA). PIN diode phase shifters are designed on a microstrip board which results in small-size and high-speed. Design criteria for switched line, loaded line and reflection type phase shifters have been developed. The network analyzer is used id the design stage to characterize the PIN diode and measure the performance of electronic phase shifters.

\subsection{RF Mixer Design}

Mixers use non-linear devices, such as microwave diodes, to achieve frequency conversion of an input signal. Therefore, device characterization becomes an important part of any mixer design. Proper device characterization also improves manufacturing yields. A vector network analyzer is used for device characterization. The microwave design software from EEsof is used with the vector network analyzer to download the device characteristics directly into the computer. Several experiments for computer aided design and testing of single-ended, balanced and double-balanced mixers have been developed.

\subsection{LNA and LNB Design}

Low Noise Amplifiers (LNA) and Low Noise Block down-converters (LNB) are the most critical circuits in the design of satellite receivers. The design criteria for several LNA and LNBs in the VHF, UHF, L, S, C and Ku bands have been developed and some have already been designed and tested. The equipment purchased by the NSF grant has enabled the students to properly characterize these devices and measure the pertinent parameters.

\subsection{Microwave Filter Design}

Discrete or distributed filters having specific requirements are necessary blocks in any RF and microwave signal processing system. Microstrip filters using step-down, edge-coupled or quarter wavelength transmission lines have been designed and tested..

In some filter applications (such as multiplexing filters) it is important to have a linear phase response in the passband to avoid signal distortion. Therefore, the phase response of the filter must be deliberately synthesized so that the group delay becomes a maximally flat function of the frequency. The vector network analyzer is used to measure the filter group delay as a function of frequency.

\section{8 -Phase-Locked Loop and Frequency Synthesizers}

In most modern microwave and satellite communication systems, phase-locked loop and frequency synthesizers are used as local oscillators, programmable tuners, FM modulators and demodulators. The stability of phase-locked loop circuits at frequencies up to $18 \mathrm{GHz}$ have been investigated and several design criteria have been developed. The Series IV software can be used 
to design and measure the responses of different components of phase-locked loops and frequency synthesizers.

\subsection{Software Application}

Recently Hewlett Packard has donated the latest release of HP-EEsof Series IV/PC software to Penn State Harrisburg. The Series IV/PC software includes: Touchstone Design Suite, Libra Design Suite, Statistical Design Package, Linear, Nonlinear, Transient and Convolution Simulators and several Component Libraries. The Touchstone software is a frequency domain linear simulator which can be used to download the device's characteristic data from the vector network analyzer into the computer. The Libra program is a linear/nonlinear simulator which can perform non-linear modeling based on device characteristics. The Libra program also performs yield analysis which takes into account parameters such as component tolerances, temperature coefficients, and S-parameter variations. The Transient Simulator performs transient analysis on linear and non-linear circuits. The ESYN program uses device characteristic data to perform noise analysis and impedance matching. The Series IV software has been integrated with the microwave engineering course which deals with the theory and design of microwave circuits.

\section{$\underline{\text { References }}$}

1. Microwave Engineering by: David M. Pozar, Addison-Wesley, 1990.

2. Microwave Circuit Design by G.D. Vendelin, John Wiley, 1990.

3. Microwave and RF Circuits: Analysis, Synthesis and Design, by M. W. Medley, Jr., 1993.

4. Behagi, A. "Development of a Computer-Based Satellite Communication Course at Penn State

Harrisburg, Journal of Engineering Technology, pp. 25-29, Spring, 1990.

5. HP EEsof Series IV/PC Documentation

\footnotetext{
ALI BEHAGI

Dr. Behagi is an Associate Professor of Electrical Engineering at Penn State University in Harrisburg since 1986. His research interest includes design and evaluation of wireless and satellite communication circuits such as lownoise amplifiers, voltage-controlled oscillators and phase-locked loop frequency synthesizers. Dr. Behagi earned his Ph.D. from the University of Southern California and his M.Sc. from the University of Michigan both in Electrical Engineering.
} 